\title{
Electric fields in LVDC cables
}

DOI:

10.1109/ICSD.2013.6619680

Link to publication record in Manchester Research Explorer

\section{Citation for published version (APA):}

Antoniou, D., Tzimas, A., \& Rowland, S. M. (2013). Electric fields in LVDC cables. In Proceedings of IEEE International Conference on Solid Dielectrics, ICSD/Proc. IEEE Int. Conf. Solid Dielectrics, ICSD (pp. 484-487) https://doi.org/10.1109/ICSD.2013.6619680

\section{Published in:}

Proceedings of IEEE International Conference on Solid Dielectrics, ICSD|Proc. IEEE Int. Conf. Solid Dielectrics, ICSD

\section{Citing this paper}

Please note that where the full-text provided on Manchester Research Explorer is the Author Accepted Manuscript or Proof version this may differ from the final Published version. If citing, it is advised that you check and use the publisher's definitive version.

\section{General rights}

Copyright and moral rights for the publications made accessible in the Research Explorer are retained by the authors and/or other copyright owners and it is a condition of accessing publications that users recognise and abide by the legal requirements associated with these rights.

\section{Takedown policy}

If you believe that this document breaches copyright please refer to the University of Manchester's Takedown Procedures [http://man.ac.uk/04Y6Bo] or contact uml.scholarlycommunications@manchester.ac.uk providing relevant details, so we can investigate your claim.

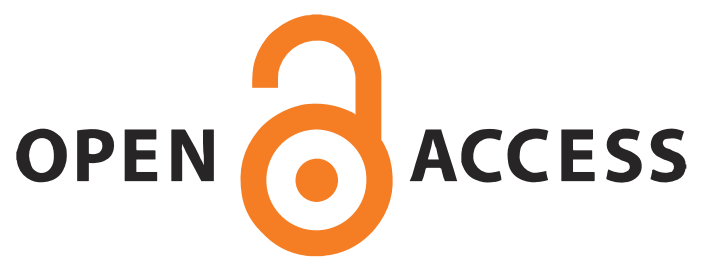


This is the accepted manuscript, which has been accepted by IEEE for publication.

(C) 2013 IEEE. Personal use of this material is permitted. Permission from IEEE must be obtained for all other uses, in any current or future media, including reprinting/republishing this material for advertising or promotional purposes, creating new collective works, for resale or redistribution to servers or lists, or reuse of any copyrighted component of this work in other works. The full reference is:

\section{'Electric fields in LVDC cables'}

D. Antoniou, A. Tzimas, and S. M. Rowland IEEE International Conference on Solid Dielectrics (ICSD) 2013 , Page(s): 484 - 487

Digital Object Identifier: 10.1109/ICSD.2013.6619680 


\title{
Electric Fields in LVDC cables
}

\author{
D. Antoniou, A. Tzimas and S. M. Rowland \\ The University of Manchester \\ School of Electrical and Electronic Engineering \\ M13 9PL, UK
}

\begin{abstract}
The operation of legacy LVAC distribution cables under DC is considered in this work. The electric field distribution in cable insulation under DC voltage is governed by the electrical conductivity of the material unlike the AC case where it is dependent on the permittivity of the materials. Temperature, water ingress and chemical ageing can increase the conductivity of the insulation. A good insulator should exhibit the least conductivity possible in order to minimise the current flowing through the material. Variations in insulation properties leading to reduced uniformity could cause local elevated stresses in the insulating material which could lead to cable failure. This paper shows how the electric field distribution in typical LVAC cables changes as the conductivity of the insulation is altered due to changes in temperature and electric field when operated under DC. A 4-core Paper Insulated Lead Covered (PILC) belted cable is simulated in COMSOL Multiphysics both under AC and DC conditions and the results are compared.
\end{abstract}

\section{INTRODUCTION}

This work is part of the 'Top and Tail Project', a collaborative project funded by the EPSRC Grand Challenge Programme. The project is focused on the physical infrastructure change in energy networks required to move the UK to a low carbon economy necessary to achieve the Government's target of reducing CO2 emissions by 2050. The project is divided in to two parts, the 'Top' and the 'Tail', and intended to be high risk and long-term in nature. The 'Top' focuses on the Transmission part of the network whereas the 'Tail' focuses on the last mile of the Distribution network. This work reported here is part of the 'Tail'.

The purpose of this work is to consider the feasibility of operating existing LVAC underground cables under DC. Using the existing infrastructure is potentially more economical and less time consuming than relaying new cables in urban environments. Studies have shown that the use of DC in the distribution network can substantially increase the power transfer in the network [1]. This assumes that the cables will operate as reliably under DC as they do under AC.

The power capacity of the present LVAC distribution network is limited by the voltage of the system. Increasing the current is not the best solution since there will be an increase in the heat produced thus increasing the losses in the system. The insulation in an AC cable is rated at the peak operating voltage. In a typical $230 \mathrm{~V}_{\text {rms }} \mathrm{AC}$ system the peak voltage is $325 \mathrm{~V}_{\text {peak }}$. A question is raised from this: "Could the system be reliable at $325 \mathrm{~V}_{\mathrm{DC}}$ ?". Extensive research has been carried out on HVAC and HVDC cables and the breakdown mechanisms are relatively well known. LVAC cables do not exhibit the breakdown phenomena present under high voltages and they are known to be very reliable. As a result little research has been carried out. A key difference between the AC and DC cases is that the electric field distribution under $\mathrm{AC}$ depends on the permittivities of the dielectrics whereas under DC it depends on the conductivity of the materials [2]. As a result, water ingress presents different issues in AC and DC cables since water changes both the permittivity and the conductivity. Conductivity is also more affected by changes in temperature and the local electric field in the insulation and so must also be considered for DC cables.

The most common paper insulated cable used in the UK distribution network is the 4-core PILC BS6480 cable [3]. The cable is rated at $600 / 1000 \mathrm{~V}$ (phase to ground/ phase to phase). FEM simulations using COMSOL are used in this work to analyse how the electric field behaves in the cable under DC. The Joule heating module is used to calculate the heat generated due to the resistance of the cable. The Electric circuit module is coupled with the Joule heating model to provide a means of changing the load for each core in the cable. Electric field stress distribution is compared for both AC and DC under normal conditions as well as in the presence of a gas filled voids and moisture.

\section{MODELling Of The CABLE}

The structure of the cable is shown in Figure 1. The cable consists of four copper conductors, three for the live AC phases and one for neutral. Paper insulation is applied to all conductors and, in the case of this belted design, an extra layer of insulation exists around all conductors. The lead sheath is usually grounded.

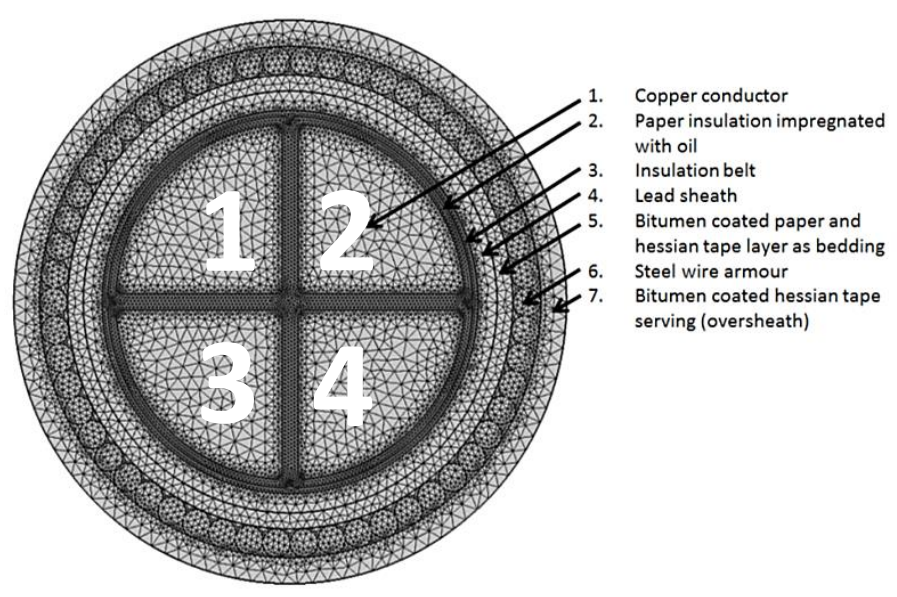

Figure 1 - 4-core $(600 / 1000 \mathrm{~V})$ paper insulated cable mesh 
Covering the lead sheath there is a layer of either a steel wire or tape armour used to provide stiffness and protection to the cable. The last layer of the cable is the oversheath (jacket) which is usually made of PVC or bitumen. The neutral is separated from the earth which usually is connected to the sheath and armour wires.

In this model the effect of strand geometry is not included, and the field is discussed in areas of greatest geometrical uniformity in the insulation so that the impact of dielectric properties can be easily considered. Careful planning was carried out to determine the minimum number of elements required to obtain sufficiently accurate results and 80,000 elements were used for meshing the initial model. After the introduction of a void into the model insulation material, manual meshing was used to eliminate rough edges on interfaces which could falsely suggest an enhanced local field. Roughly 100,000 elements were used for the void model and around 160,000 where used for the introduction of moisture. Table 1 show the material properties used in the simulation and Table 2 the domain parameters.

The copper conductors in the cable are stranded but for simplification the electrical conductivity of copper was reduced to compensate for the packing factor. Convective cooling was applied on the outermost surface of the cable. Depending on the study, different voltage levels were applied on the four conductors. The lead sheath was always kept at ground potential. Similarly temperature conditions were altered depending on the study and are discussed further on.

Table 1 - Material properties used in the simulation

\begin{tabular}{|l|c|c|c|c|c|c|c|}
\cline { 2 - 8 } \multicolumn{1}{c|}{} & Copper & Steel & PVC & $\begin{array}{c}\text { Paper } \\
\text { insulation }\end{array}$ & Lead & Air & Water \\
\hline $\begin{array}{l}\text { Electrical Cond. } \\
(\mathrm{S} / \mathrm{m})\end{array}$ & $6.0 \times 10^{7}$ & $4.0 \times 10^{6}$ & $1.0 \times 10^{-15}$ & $1.0 \times 10^{-16}$ & $4.6 \times 10^{6}$ & $5.0 \times 10^{-15}$ & $5.5 \times 10^{-4}$ \\
\hline $\begin{array}{l}\text { Thermal Cond. } \\
\left(\mathbf{W} /\left(\mathrm{m}^{*} \mathrm{~K}\right)\right)\end{array}$ & 400 & 44.5 & 0.10 & 0.11 & 35 & 0.025 & 0.60 \\
\hline $\begin{array}{l}\text { Heat Capacity } \\
\left(\mathrm{J} /\left(\mathrm{kg}^{*} \mathrm{~K}\right)\right)\end{array}$ & 385 & 475 & 2300 & 1200 & 130 & 1012 & 4181 \\
\hline $\begin{array}{l}\text { Relative } \\
\text { permittivity } \\
\left(\varepsilon_{\mathrm{r}}\right)\end{array}$ & 1.0 & 1.0 & 8.0 & 3.6 & 1.0 & 1.0 & 80 \\
\hline $\begin{array}{l}\text { Density } \\
\left(\mathrm{kg} / \mathrm{m}^{3}\right)\end{array}$ & 8700 & 7850 & 1760 & 1200 & 11340 & 1.184 & 1000 \\
\hline $\begin{array}{l}\text { Initial } \\
\text { Temp. }\left(^{\circ} \mathrm{C}\right)\end{array}$ & 25 & 25 & 25 & 25 & 25 & 25 & 25 \\
\hline $\begin{array}{l}\text { Heat transfer } \\
\text { coefficient } \\
\left(\mathbf{W} / \mathrm{m}^{2} \mathrm{~K}\right)\end{array}$ & & & & & & 7 & \\
\hline
\end{tabular}

Table 2 - Domain parameters

\begin{tabular}{|l|c|}
\cline { 2 - 2 } \multicolumn{1}{c|}{} & Parameters \\
\hline Nominal area of each conductor & $120 \mathrm{~mm}^{2}$ \\
\hline Conductor insulation thickness & $0.7 \mathrm{~mm}$ \\
\hline Insulation belt thickness & $0.5 \mathrm{~mm}$ \\
\hline Sheath thickness & $1.7 \mathrm{~mm}$ \\
\hline Bedding thickness & $1.4 \mathrm{~mm}$ \\
\hline Armour thickness & $2.5 \mathrm{~mm}$ \\
\hline Oversheath thickness & $2.3 \mathrm{~mm}$ \\
\hline
\end{tabular}

\section{DC CONDUCTIVITY}

The electrical conductivity depends on the temperature and the electric field in the insulation [4]. Equation 1 is an empirical formula relating the conductivity to temperature and electric field where $k_{o}$ is the specific electrical conductivity at $0^{\circ} \mathrm{C}$ and zero field, $T$ is the temperature difference from $0^{\circ} \mathrm{C}\left(\mathrm{T}_{1}-273\right)$ in $\mathrm{K}, T_{1}$ is the local insulation temperature in $\mathrm{K}, E$ is the electric field in $\mathrm{kV} / \mathrm{mm}, a$ is the temperature coefficient of conductivity and $\beta$ is the electric field strength coefficient of conductivity.

$$
k(\vartheta,|E|)=k_{0} \cdot \exp (\alpha \cdot \mathrm{T}) \cdot \exp (\beta \cdot|\mathrm{E}|)
$$

This formula was entered as a conductivity expression in the FEA tool. Values from the literature of $\alpha$ and $\beta$ were assumed to be 0.1 and 0.03 respectively [5].

\section{ElECTRIC FIELD Distribution IN THE CABLES}

Other parameters that can affect the electric field distribution are the geometry of the cable and/or any imperfections present in the insulation. Given a uniform conductivity, the highest electric field should be close to the conductor rather than the sheath. In this study the model was coupled to circuit physics. This module allowed simulation of the current flowing through each conductor which was fed back to the Joule Heating module. Conductors 1,2 and 4 were run at $265 \mathrm{~A}$ each. The maximum temperature observed was $57.4{ }^{\circ} \mathrm{C}$ at the cores. The sheath temperature was $54{ }^{\circ} \mathrm{C}$ creating a temperature gradient of $3.4{ }^{\circ} \mathrm{C}$. Figure 2 shows the cutline used to plot the graph in Figure 3. A field inversion occurs at around 6000 seconds. After that the highest electric field is adjacent to the sheath rather than the conductor. At a temperature gradient of just 3.4 ${ }^{\circ} \mathrm{C}$ the largest variation of electric field was observed to be an increase of around $75 \mathrm{~V}_{\mathrm{dc}} / \mathrm{mm}$ between conductor and sheath with the average being $270 \mathrm{~V}_{\mathrm{dc}} / \mathrm{mm}$. Stranded conductors would enhance the field locally and the highest field would be at conductor edges but this would not change the fact that under DC the field will be higher at several points due to the inversion effect compared to AC.

Different loading conditions on each conductor could increase the temperature gradient but given such a small thickness it might prove to be insignificant. At higher electric field stresses, inversion could facilitate the accumulation of space charge [1], but this seems unlikely in LV cables.

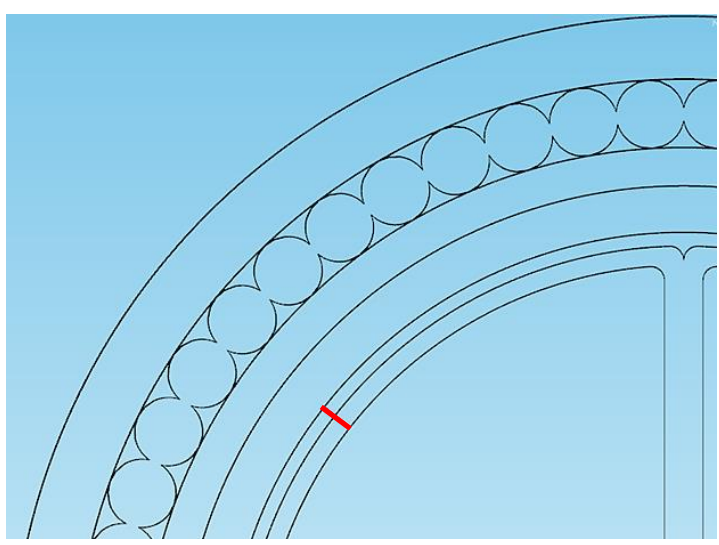

Figure 2 - Cutline used to plot the graph in Figure 3 


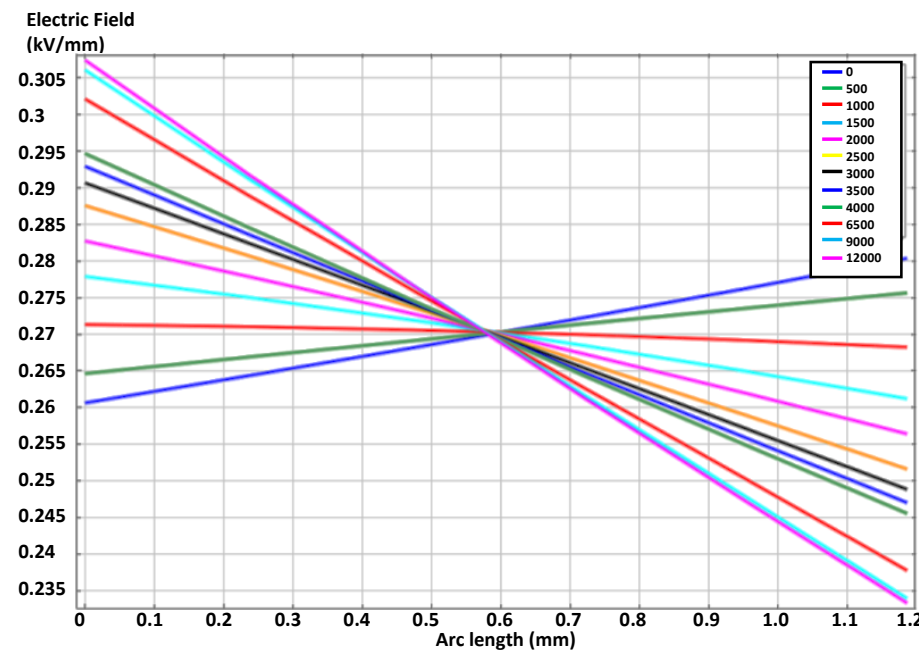

Figure 3 - Electric field across the insulation, as a function of time. Colour lines are at different times (seconds).

\section{TEMPERATURE EFFECTS}

Field inversion can be increased by increasing the temperature differences in the cable. To better demonstrate the effect, temperature boundary conditions were set on the conductors and sheath. The temperature difference was raised to $7.4{ }^{\circ} \mathrm{C}$. Two studies were run, one DC and the other AC. In the DC study, conductors 1 and 2 were set at $325 \mathrm{~V}$, and conductors 3 and 4 earthed. In the AC study, conductors 1, 2, and 4 were three phase at $230 \mathrm{~V}_{\text {rms }}$, and conductor 3 earthed. The simplest geometrical cutline, shown in Figure 2, is used to illustrate results so only the phase to ground electric field is considered in this study. Figure 4 shows the results from the DC study. A variation of around $0.16 \mathrm{kV} / \mathrm{mm}$ between conductor and sheath is observed. The average is still at 0.27 $\mathrm{kV} / \mathrm{mm}$ since the voltage and insulation thickness have not changed.

Figure 5 shows the results of the AC study. These cycles were taken after a sufficient time in order to reach temperature equilibrium. Six points on the first half crest of the waveforms are plotted ranging from $0 \mathrm{~V}$ to a peak of $325 \mathrm{~V}$.

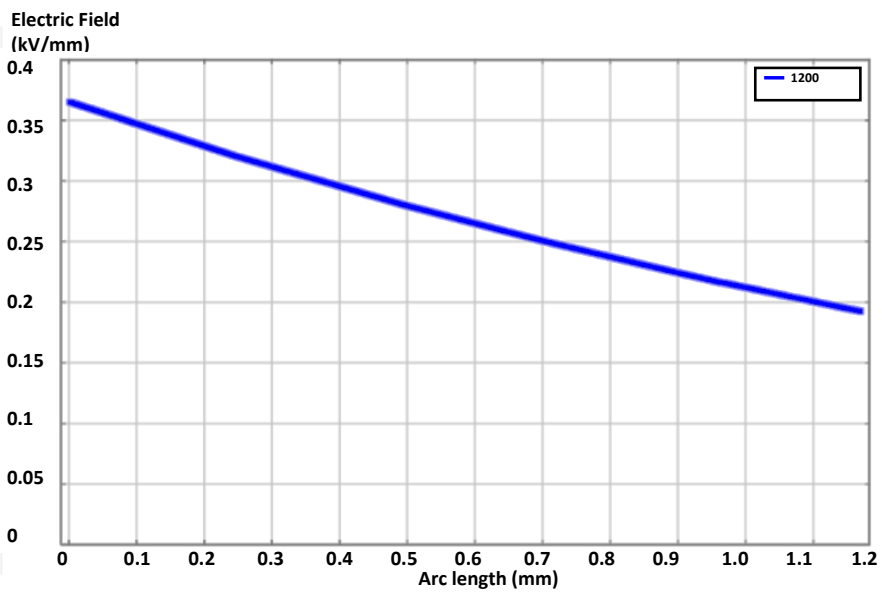

Figure 4 - Electric field under DC with a $7.4^{\circ} \mathrm{C}$ gradient

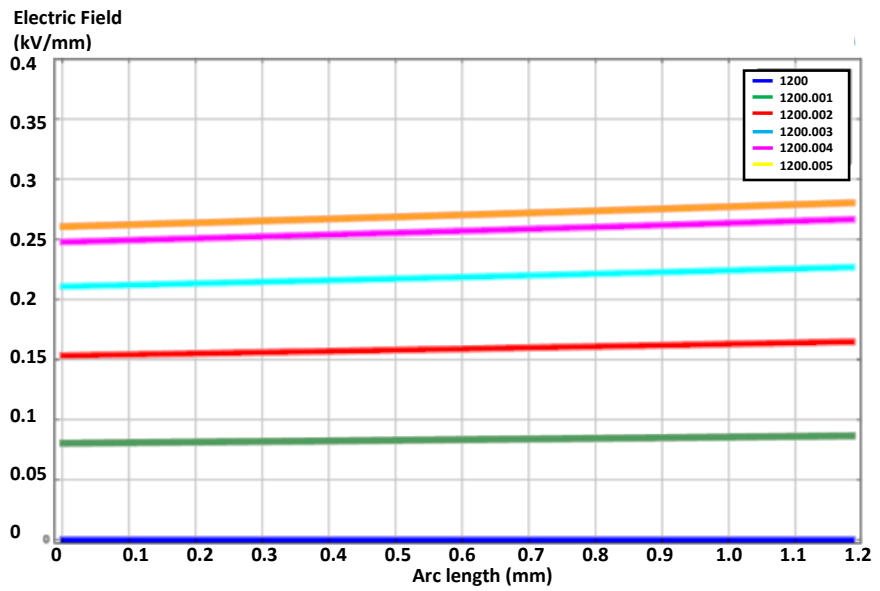

Figure 5 - Electric field under $\mathrm{AC}$ with a $7.4^{\circ} \mathrm{C}$ gradient, within an $\mathrm{AC}$ quarter cycle. Coloured lines are at different times (seconds).

The graph shows the maximum electric field at $0.28 \mathrm{kV} / \mathrm{mm}$ at the conductor side due to geometry. What should be noticed is that under $\mathrm{AC}$ the electric field never reaches the maximum electric field seen under DC. Under DC there is a constant high electric field near the sheath whereas under $\mathrm{AC}$ is more uniform. The insulation under DC would be subjected to a continuously high field (polarity reversals being unlikely in the distribution network) whereas under $\mathrm{AC}$ it will continually reverse polarity. At these low voltages this might prove to be insignificant but in an aged cable, temperature variations could be great further enhancing the effect.

\section{EFFECTS OF IMPERFECTIONS}

Imperfections in the insulation such as voids may cause the insulation to breakdown. In $\mathrm{HV}$ cables partial discharge is mainly responsible for this phenomenon [6]. The voids are gas filled thus having a lower dielectric constant. This causes a higher electric field inside the void. Air has a lower dielectric strength than the insulation therefore a partial breakdown occurs in the void. An elliptical void was introduced in the model with: an X-radius of $100 \mu \mathrm{m}$, a y-radius of $50 \mu \mathrm{m}$ and a z-radius of $50 \mu \mathrm{m}$. Void geometry can greatly impact the local electric field. Studies on how different geometries enhance the field are well established [7]. This study concentrates on the enhancement due to different currents rather than different geometries.

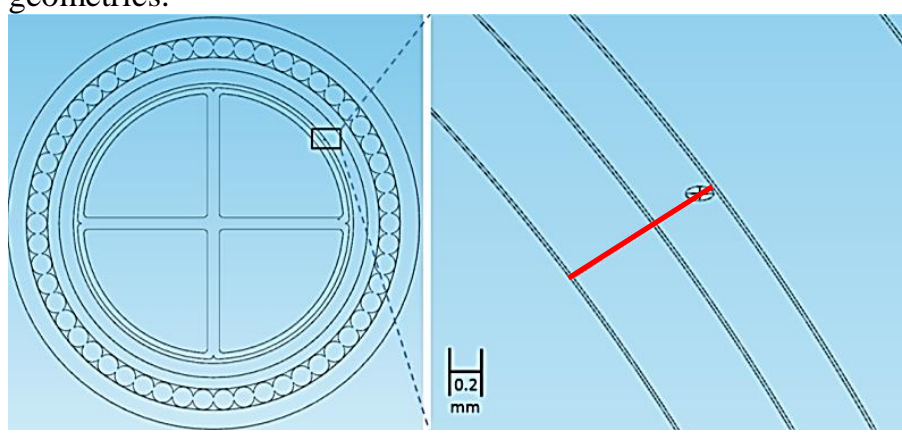

Figure 6 - Position and size of the void 


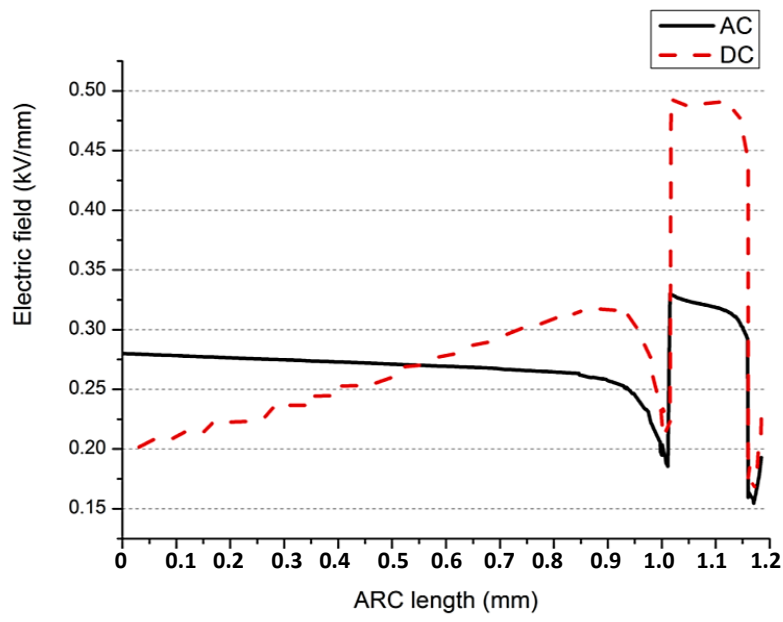

Figure 7 - Electric field enhancement as a result of the void.

Figure 6 shows the void in the cable insulation belt and a new cutline is shown. In Figure 7 the graph compares the field enhancement in AC and DC cases and again the enhancement is greater under DC. Placing the void between two conductors will give results according to the voltage levels. This will not however change the fact that conductivity changes with temperature, and as a result, changes the electric field distribution under DC. The of the fields in the DC case may be larger, but the fields are still well less than $1 \mathrm{kV} / \mathrm{mm}$, and these voltages are not enough to cause discharges in such voids. Paschen's law indicates that conventional models of partial discharge associated with high voltage insulation will not occur at voltages lower than $350 \mathrm{~V}$ which is above the maximum voltage to be seen in a void in this system configuration.

\section{MOISTURE EFFECTS}

Moisture was introduced into the model. Figure 8 shows the arrangement of the water content and the field distribution. In reality, the volume, spatial distribution and properties of the water will greatly vary from one cable to the other. The field enhancement is higher than previous cases considered. The voltage potential distribution is not uniform between conductor and sheath anymore and the electric field increases. This, along with the change in geometry, causes a higher local electric field. Under DC the electric field is still higher than under AC.

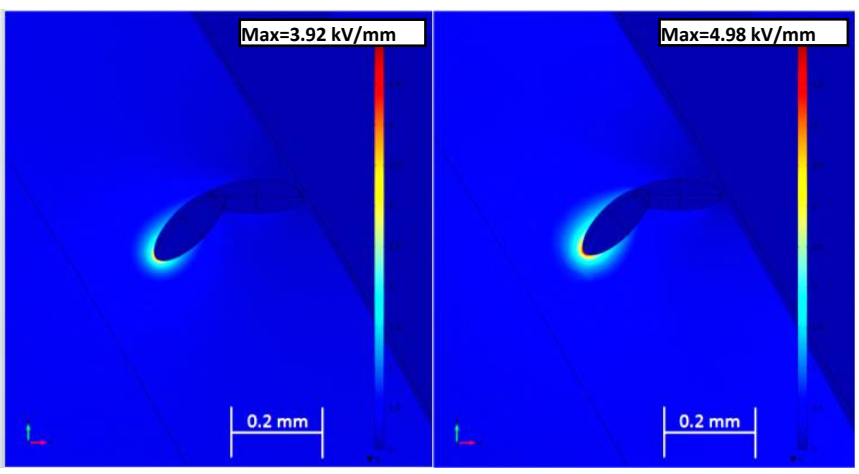

Figure 8 - Electric field distribution with water present
The field created by the water ingress is still not high, but it may be significant in that it may drive moisture diffusion, and the divergence it introduces may drive dielectrophoresis. Because the cable insulation is not uniform physically more work is required to understand moisture diffusion $[8,9]$.

\section{CONCLUSIONS}

The simulation of the 4-core PILC cable has shown that the electric field distribution under DC is essentially different to that in the AC case. A field inversion occurs which could facilitate space charge accumulation but at these low voltages and low electric field stresses it is unlikely to be of great importance. Under $\mathrm{AC}$, the effect of temperature variation between the conductor and sheath has no impact on the distribution of the electric field. Energising with DC results in a higher electric field towards the sheath, and so the insulation will not be uniformly stressed as in the AC case.

The presence of imperfections further cause enhancement in localised fields and will be higher under DC. Nonetheless the low voltages of a few hundred volts are insufficient to allow partial discharge by the classical models associated with high voltage cables. In the presence of water, DC will produce a greater electric field enhancement compared to AC. A key issue is whether such fields can drive moisture migration. Equally importantly when considering an existing network will be to consider the behaviour of existing joints in networks [10].

\section{ACKNOWLEDGMENTS}

The authors gratefully acknowledge the RCUK's Energy Programme for the financial support of this work through the Top \& Tail Transformation programme grant, EP/I031707/1 (http://www.topandtail.org.uk/).

\section{REFERENCES}

[1] Tzimas, A.; Antoniou, D.; Rowland, S.M., 'Low voltage DC cable insulation challenges and opportunities' Conference on Electrical Insulation and Dielectric Phenomena, pp. 696-699, 2012

[2] Morshuis P.H.F., Roefs R.J., Snitt J.J., Contin A., Montinari G.C., 'The stability of mass-impregnated paper AC cables operated at DC voltage' Proc. JiCable, 1999

[3] British Standard BS6480, 1988

[4] Shanshan Qin and Boggs, S., 'Design considerations for high voltage DC components' Electrical Insulation Magazine, IEEE, vol.28, no.6, pp.36-44, Nov.-Dec. 2012

[5] Electric Cables Handbook - BICC Cables, third Edit., pp. 575-576, 1997

[6] Dissado, L. A., and Fothergill, J. C., 'Electrical Degradation and Breakdown in Polymers' Peter Peregrinus for IEE: London, 1992

[7] Blackburn, H. N. O; T. R., Phung, B., Zhang, T. H., Khawaja, R. H. "Investigation of Electric Field Distribution in Power Cables with Voids," Int Conf. on Properties and Applications of Dielectric Materials, 637-640, 2006

[8] Rowland, S. M., and Wang, M., 'Fault Development in Wet, Low Voltage, Oil-Impregnated Paper Insulated Cables' IEEE Trans DEI 15 Issue 2, 484-4912008

[9] Wang, M., Rowland, S. M., and Clements, P. E., 'Moisture Ingress into Low Voltage Oil-Impregnated-Paper Insulated Distribution Cables' IET Proc Sci., Meas. \& Tech. 1 Issue 5, 276-283, 2007

[10] Antoniou, D., Tzimas, A., Rowland, S. M., 'DC utilization of existing LVAC distribution cables' Electrical Insulation Conference, 2013 